\title{
Mismanaging Unethical Behaviour In The Workplace
}

Prakash Singh, Nelson Mandela Metropolitan University, South Africa

Thembinkosi Twalo, Human Sciences Research Council, South Africa

\begin{abstract}
What constitutes unethical behaviour and its mismanagement is the focus of this article. This includes the transgression of moral norms by employees such as greed, corruption, antisocial behaviour and the abuse of company assets for personal enrichment. A salient feature of this case study is its focus on the workers' lack of adherence to its ethics policies, and a conscious flagrant disregard for the organization's moral codes by its employees. The research question that inevitably arises is whether the employees resort to unethical behaviour because they fail to achieve their goals through legitimate means, or whether it is simply a flagrant disrespect by them of organizational ethical policies that enunciate the moral norms for all its employees. This exploratory study used the mixed methods approach to investigate this problem. The research findings of this study strongly suggest why the sustainability of an organization can be threatened by reported cases of poor administration, weak management of human and non-human resources, and inappropriate job behaviour and performance of its employees. A key finding is that organizations should not leave managers and their employees to solely rely on their moral intuition and good judgement, but to create a culture with the aid of a performance management system in which there is a clear distinction between ethical and unethical behaviour. This research therefore provides further insight into the need for organizations to develop effective management strategies in order to prevent, detect, and respond forcefully to stamp out unethical behaviour of its employees.
\end{abstract}

Keywords: Employees' Unethical Job Behaviour; Weak Management; Organizational Ethical Policies; Performance Management System

\section{INTRODUCTION}

$\mathscr{Q}$ nethical behaviour of employees in the workplace not only threatens the reputation of the affected organizations, but also has a devastating effect on these organizations' ability to render quality services to its customers and other stakeholders. It undermines and harms human relations (Kaptein, 2011; Treviño, Weaver, \& Reynolds, 2006). One of the greatest challenges facing any organization is therefore the mismanagement of the unethical behaviour of its employees. This can even impact negatively on the continuity of organizations (Grant \& Visconti, 2006) and consequently, it would not be unexpected for disaffected stakeholders to place pressure on management to effectively stamp out unethical practices in the workplace (Kaptein, 2008; Treviño, Weaver, \& Reynolds, 2006). Stakeholder theory posits that business organizations have multiple relationships with all kinds of individuals, groups and organizations and these stakeholders enter into a relationship with business organizations to protect their interests (Freeman, 1984; Donaldson \& Preston, 1995; Jones \& Wicks, 1999; Mitchell, Agle, \& Wood, 1997). It can therefore be argued that mutual expectations can arise between both parties demanding that they engage with each other's interests in an ethically accountable manner, and it would be imperative that organizations shoulder an ethical responsibility to support and promote the interests of their stakeholders (Kaptein, 2008; Brass, Butterfield, \& Skaggs, 1998). If employees, for example, steal or misappropriate organizational assets, then this can severely strain the relationship between the organization and its financiers, and this can damage the financial reputation of the organization (Mazzola, Ravasi, \& Gabbioneta, 2006). Such misdemeanours can be the result of mismanagement when checks and balances in a performance management system (PMS) are not meticulously implemented in the organization. Hence, it is not unexpected that in view of the 
financial and reputational costs, organizations will constantly face the challenge of preventing, detecting, and responding timeously to unethical behaviour (Kaptein, 2011; Kidwell \& Martin, 2005; Goodpaster, 2007).

What constitutes unethical behaviour and its mismanagement is the focus of this article. This includes the transgression of moral norms that include greed, corruption, antisocial behaviour and abuse of company assets for personal enrichment (Giacalone \& Greenberg, 1997; Vardi \& Weitz, 2004; Bennett \& Robinson, 2000; Treviño \& Weaver, 2003). Business ethics comprise rules, standards, principles, or codes providing guidelines for morally sound behaviour (Singh \& Twalo, 2014), and unethical behaviour implies the violation of these moral norms (Kaptein, 2008). The ethical culture of any organization is sacrosanct, and its policies are regarded to be a significant component of the organizational culture to account for unethical behaviour (Kaptein, 2011). Research by Kaptein (2011) affirms that managers are expected to be role models, but fail to be so when they communicate contradictory or inconsistent signals to subordinates. A salient feature of this case study is its focus on the Buffalo City Metropolitan Municipality (BCMM) workers' lack of adherence to its ethics policies, and a conscious flagrant disregard for its moral codes by its employees (Times Live, 2010). The research question that arises is whether employees in the BCMM resort to unethical behaviour because they fail to achieve their goals through legitimate means, or is it simply a flagrant disrespect by them of organizational ethical policies that enunciate the moral norms for all its employees. Of importance is that organizations such as the BCMM do not leave managers and their employees to solely rely on their moral intuition and good judgement, but to create a culture with the aid of a PMS in which there is a clear distinction between ethical and unethical behaviour (Kaptein, 2011). Hence, an important objective of this study was also to determine whether the unethical behaviour occurred in the absence of a clear normative framework in the organization. This research therefore provides further insight into the need for organizations to develop effective management strategies as part of its PMS in order to prevent, detect, and respond forcefully to stamp out unethical behaviour of its employees.

\section{MISMANAGEMENT OF ETHICAL STANDARDS}

An effective PMS should facilitate decision-making concerning strategy development and increased accountability, create maximum opportunities for work-integrated learning for all its employees, and provide early warning signals when the culture of best practices in the organization is violated (Overstrand, 2014). Behaviour that is consistent with the ethical standards of any organization will reinforce the message of compliance with these standards when managers serve as role models to their subordinates (Bandura, 1997; Schein, 1985; Brown, Treviño, \& Harrison, 2005). Research on unethical behaviour of employees (Kaptein, 2011; Brown, Treviño, \& Harrison, 2005; Brown \& Treviño, 2006; Hegarty \& Sims, 1979; Dineen, Lewicki, \& Tomlinson, 2006; Schminke, Ambrose, \& Neubaum, 2005) clearly indicates that ethical standards in organizations are compromised by unethical role modelling by managers as employees often imitate the ethical or unethical behaviour of their managers. Recently, leaders have been coming under increasing scrutiny not only because many senior executives are accused of having committed unethical acts, but also because of the role that leaders at all levels are thought to play in managing the unethical conduct of their employees (Treviño \& Brown, 2005). Tang, Chen, and Sutarso (2008) in their aptly titled article: Bad apples in bad (business) barrels, argue that "for unethical behaviour, people usually start out something small early in their lives, then inch by inch, they dig deeper and deeper into a hole which they cannot get out" (p. 245). Using the analogy of a machiavellian, they assert that employees who employ "aggressive, manipulative, exploitive, and devious methods to achieve goals will have a high propensity to engage in unethical behaviour" ( $p$. 248). This problem is further compounded when employees believe that unethical behaviour, as opposed to legitimate means, can enable them to achieve their personal goals (Treviño, 1986; Merton, 1938). In addition, when employees have insufficient resources or means to meet organizational goals, employees would rationalize their unethical behaviour, instead of paying particular attention to ethical standards to carry out their responsibilities (Kaptein, 2011; Robertson \& Rymon, 2001; Schweitzer, Ordonez, \& Douma, 2004).

Performance management is supposed to create a direct link between employee performance and organizational goals (Aguinis, 2005). It makes the workers' contributions to the organization explicit. A PMS that fails to make explicit employee contributions to the organization cannot be classified as a suitable PMS. Therefore, a poorly implemented PMS can have a devastating effect on the morale of workers when internal factors such as discrimination, unfair treatment of workers, and lack of recognition of excellence in exceeding job expectations (Singh \& Twalo, 2014). This can incite workers to engage in unethical behaviour because they do not feel attached, 
or even committed to the organization because a culture characterized by mistrust and poor interpersonal relationships between managers and their workers can be a breeding ground for unethical behaviour (Kaptein, 2011; Greenberg, 2002; Boye \& Jones, 1997; Hirschi, 1969). Mismanagement of employees' unethical behaviour implies that there are situations when managers and their employees are ignorant of the grave consequences of their behaviour, and consequently would be deprived of the opportunity to account for and alter their behaviour (Kaptein, 2011; Hollinger \& Clark, 1983). This can result in the concealment of the unethical behaviour, and the frequency of its occurrence without its detection because of poor management. Singh's research on tobephobic leadership (2013a; 2013b) reveals that a lack of collegial leadership in an organization can sow fear of failure amongst employees. As argued by Singh (2013a; 2013b), when workers do not have the support of their leaders, then they are bound to justify their unethical behaviour.

A performance management framework (see Figure 1) is supposed to be developed and negotiated between employers and their employees on a collegial basis. Collegial leaders will develop the PMS by facilitating shared decision-making to finalize the inputs, activities, outputs, outcomes, and the impact this process has on the organization. With such a framework firmly in place, employees would have the self-regulating capacity to selfmonitor their job behaviour and performance in order to detect the transgression of any company moral codes. This implies that they need to also constantly self-evaluate and self-reinforce ethically appropriate behaviour in the workplace (Singh, Manser, \& Dali, 2013). The organizational climate and culture must enable employees at all levels to openly discuss alleged unethical behaviour and create internal processes within the framework for selfcorrective measures to be undertaken (Kaptein, 2011). Their commitment has to be intrinsically motivated. As part of this case study focusing on the BCMM, the issue of candidly discussing the unethical behaviour of employees in the organization was also investigated.

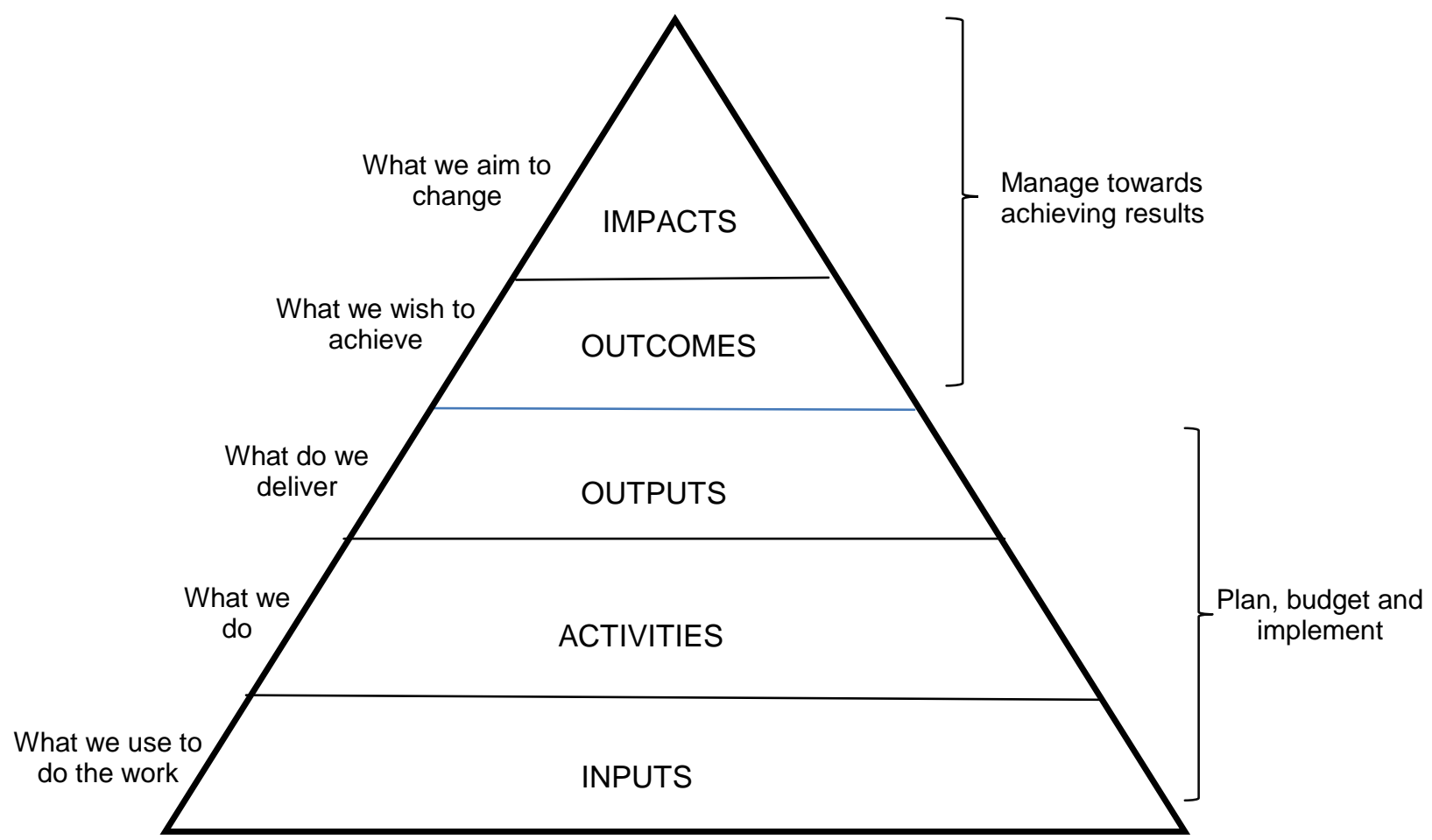

Source: Overstrand, 2014, p. 27

Figure 1: Performance Management Framework

A multidimensional approach is therefore adopted in this study to investigate the mismanagement of unethical behaviour in the workplace since different settings can influence the relation between the dimensions of ethical culture and unethical behaviour (Kaptein, 2011). The evidence thus far suggests that the BCMM is characterised by maladministration, mismanagement and misappropriation of resources (Mawonga, 2012; Benya, 2011; Times Live, 2010). Even the Auditor General rated the BCMM as the worst metropolitan council in South 
Africa in the 2010/11 audit (Times Live, 2012). The Auditor General, in his latest report (Mokone \& De Kock, 2014), attests that this reflects a concerning picture of the drivers of the internal control environment, a lack of policies, procedures and controls for document management, the absence of daily and monthly financial controls, as well as poor monitoring of compliance with legislation.

\section{METHODOLOGY}

This study used the mixed method approach, that is, a combination of qualitative and quantitative research methods (Creswell \& Plano-Clark, 2007). The investigation merited a mixed method approach because mixing the qualitative and quantitative data helped to provide a better understanding of the municipal workers' job behaviour and performance at the BCMM since limited data would have been collected only if either method had been used. Qualitative methods included an analysis of relevant literature and semi-structured interviews with sampled workers from various departments and in different ranks. The quantitative method was in the form of a questionnaire with 79 closed-ended questions, which included 10 biographical questions. The questionnaire had 6 qualitative questions, thus the total number of questions was 85. BCMM workers were requested to complete and return the questionnaire that was sent to them by email and fax, and later hand delivered.

As of 30 June 2012, the BCMM had 8 directorates, 39 departments and a total staff complement of 5427 (Buffalo City Metropolitan Municipality, 2012). Ten respondents per department were meant to be sampled for responding to the questionnaire, so as to have 390 respondents in total. For the structured interviews, 1 person was intended to be sampled per directorate, so as to have 8 interviewees in total. However, due to fieldwork logistics that included a high rate of refusal to participate in some departments, the share of respondents per department could not be balanced. Consequently, some departments were over-represented and others were under-represented. In lieu of getting 398 respondents ( $7 \%$ of the total staff complement), only 342 (6\% of the total staff complement) could participate. However, physically administering the questionnaire around the BCMM offices meant that the respondents were much more than 342 . This is because the researcher had to explain to the workers, including those who refused to complete the questionnaire, what the questionnaire was about and, in return, they spoke about their experiences and observations at the BCMM. Refusal to complete the questionnaire was on account of lack of time by some workers, fear of victimisation because the environment was highly political, and research fatigue by those who felt that they had participated in too many research projects, yet nothing seemed to change.

Purposeful sampling was employed since special attention had to be paid to staff with formal education in order to investigate the co-existence of formal education with inappropriate job behaviour and performance. However, many workers (49\%) had no matric and most of them were in elementary occupations (Buffalo City Metropolitan Municipality, 2011). The level of formal education was not made a prerequisite because most workers' education level was commensurate with their occupations. Taking these technicalities into consideration, the research questions then sought to probe how inappropriate job behaviour and performance persisted in the respective occupations despite the commensurate education credentials.

The research process and instruments were designed to enable meaningful analysis of the data, because on its own, data is meaningless unless systematically and logically interpreted. This interpretation was done through analysis of the responses against relevant laws and policies such as the Municipal Structures Act (1998), the Local Government Municipal Systems Act (2000), the BCMM supply chain management (SCM) policy and recruitment policy. For the quantitative data analysis, empirical statistical data were generated and processed by a qualified statistician from the Nelson Mandela Metropolitan University's (NMMU's) Statistics Department. Non-parametric statistical tests were conducted using SPSS version 12.0 programmes to analyse the relationships between variables. The Spearman rank correlation coefficient was used to determine the relationship between categorical variables.

The statistical significance of the variables' correlation was calculated using the chi - square test and crosstabulations of the data. For each cross-tabulation, the chi-square test is reported that indicates statistical significance, Cramer's V is also reported that indicates the practical significance (small, medium or large), and lastly Spearman rank correlation is also reported since the variables are ordinal. For measuring the internal consistency (reliability) of the instrument, Cronbach's alpha was used. The levels of reliability appeared to be high with an average of 0.75 for employees' job behaviour and an average of 0.82 for employees' job performance. 
Participation in this study was voluntary and all participants were made aware of this through the covering letter. Their confidentiality was also guaranteed with the covering letter undertaking that participants' personal details would not be disclosed under any circumstances. There would therefore be no risk of harm, embarrassment or offence to any participant or to the municipality. In fact, the biographical information section enabled them to remain anonymous since the required information was about their directorates and departments, type of employment, tenure, and educational qualifications. The covering letter also noted that there were no risks or discomforts associated with participation and it also clearly stated that there were no pecuniary benefits of participation to the participants. The participants' attention was also drawn to the fact that this research was approved by the university's Research Ethics Committee, with ethics approval number H12-EDU-ERE-028. They were assured that this committee is competent, being composed of experts whose responsibility includes ensuring that the rights and welfare of participants in this study are protected and that the study is conducted in an ethical way.

\section{DISCUSSION OF FINDINGS}

\section{Human Nature In The Labour Process}

Although most respondents thought that their qualifications were relevant to the kind of work they did on a daily basis, most respondents (59\%) were of the view that workers did not seem to care about the moral implications of their actions at work and $88 \%$ observed that some workers knew what was right, but still did what was wrong. Of the respondents who thought BCMM workers did not seem to care about the moral implications of their actions at work, 57.09\% thought that some BCMM workers knew what was right but still did what was wrong. The relationship between the two variables was found to be statistically significant $\left(\mathrm{Chi}^{2}=250.25, \mathrm{df}=16, \mathrm{p}=0.0000\right)$ with Cramér's V $=0.44$ which indicates that this finding is of large practical importance. However, the Spearman correlation coefficient (0.02) indicates that generally there was no correlation between the workers' taking into consideration of the moral implications of their actions at work and the workers' doing of what was wrong when they knew what was right. The workers' display of inappropriate behaviour when they knew what was right underscores the contradiction between education and practice. It shows that some workers, regardless of their formal education qualifications, practised inappropriate job behaviour and performance. The challenge, however, is that it is not known how many of those with formal education still practised inappropriate job behaviour and performance. Therefore, it is not possible to conclude that those who claimed to have relevant qualifications were also part of those who practised inappropriate job behaviour and performance. However, in light of the high numbers of those who observed that some workers knew what was right, but still did what was wrong, it means that there is a greater probability that those with relevant educational qualifications were also part of those who practised inappropriate job behaviour and performance at the BCMM. This sheds some light on the paradoxical co-existence of formal education with inappropriate job behaviour and performance because the fact that some workers knew what was right, but still did what was wrong, is indicative of the paucity of appropriate attitudes, ethics and values. It also underscores the role of the human nature in the labour process, because it plays a critical role in shaping the workers' job behaviour and performance. Therefore, the school of thought that attributes societal challenges such as poor service delivery, negligence, maladministration, and poor financial management to lack of skills (Kaseke, 2011; Stokes, 2010) needs to reconsider its stance, as some of these factors are not attributable to lack of capacity, but intention due to selfish personal interests.

Section 195 (1) of the South African Constitution fosters "a high standard of professional ethics" (South African Local Government Association (SALGA) 2011, p. 10). In light of the significant number of respondents who were of the view that workers did not seem to care about the moral implications of their actions at work, 39\% of the respondents were of the view that what was important when working was how the job was done and not just the results and 33\% thought the results were more important than how the job is done, while $28 \%$ had no opinion in this regard. Of the respondents who thought BCMM workers do not seem to care about the moral implications of their actions at work, $26.49 \%$ thought that what was important when working were the results and not how the job was done. The relationship between the two variables was found to be statistically significant $\left(\mathrm{Chi}^{2}=342.28, \mathrm{df}=\right.$ $16, \mathrm{p}=0.0000$ ) with Cramér's $\mathrm{V}=0.52$ which indicates that this finding is of large practical importance. The Spearman correlation coefficient $(0.48)$ indicates that there was a moderate correlation between the workers' taking into consideration of the moral implications of their actions at work and the workers' thinking that what was 
important when working were the results and not how the job was done. The placing of more importance on how the job was done than the results is indicative of the "tick a box" attitude and a mindless compliance with rules rather than taking full responsibility for one's work. This corroborates this study's hypothesis that the perpetual inappropriate job behaviour and performance at the BCMM is due to the paucity of broad skills which includes various forms of knowledge, ethics, values and attitudes. Although many BCMM workers had the required academic qualifications for their jobs, however, many did not seem to have the required ethics, values and attitudes.

\section{Factors Compromising Employees' Behaviour}

Not having the required ethics, values and attitudes could be on account of not having learnt them or their erosion due to various circumstances. Awareness of injustice, inconvenience and unfairness caused at the workplace could contribute towards the erosion of these components of broad skills or failure to apply them even if they are not eroded. Table 1 shows that different factors could play a role in compromising the job performance and behaviour of the workers and they are personal, systematic, and structural in nature.

Table 1: Extent To Which Different Attributes Compromise The Job Performance And Job Behaviour Of The Workers

\begin{tabular}{|c|c|c|c|c|c|c|c|c|c|c|c|}
\hline 苞 & 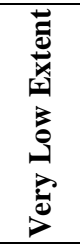 & 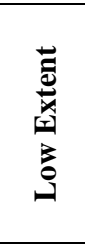 & 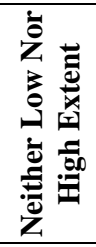 & 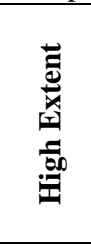 & 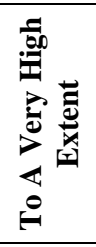 & 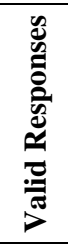 & 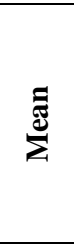 & $\begin{array}{l}\dot{\vec{U}} \\
\dot{0} \\
\dot{D}\end{array}$ & 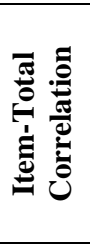 & 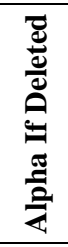 & 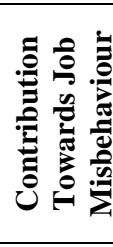 \\
\hline Ignorance & 7.67 & 28.12 & 52.40 & 5.43 & 6.39 & 313 & 2.75 & 0.91 & 0.37 & 0.69 & $12 \%$ \\
\hline Greed & 5.11 & 3.19 & 30.35 & 51.76 & 9.58 & 313 & 3.58 & 0.90 & 0.42 & 0.67 & $61 \%$ \\
\hline $\begin{array}{l}\text { Unclear job } \\
\text { procedures }\end{array}$ & 6.45 & 4.84 & 51.94 & 30.00 & 6.77 & 310 & 3.26 & 0.90 & 0.65 & 0.58 & $37 \%$ \\
\hline $\begin{array}{l}\text { Lack of security } \\
\text { for BCMM assets }\end{array}$ & 4.58 & 3.27 & 28.76 & 29.41 & 33.99 & 306 & 3.85 & 1.07 & 0.43 & 0.67 & $63 \%$ \\
\hline $\begin{array}{l}\text { Protection for } \\
\text { those accused of } \\
\text { job misbehaviour }\end{array}$ & 6.27 & 3.63 & 32.01 & 28.05 & 30.03 & 303 & 3.72 & 1.12 & 0.46 & 0.66 & $58 \%$ \\
\hline
\end{tabular}

To get the percentages in Table 1, the last two options (to a high extent and to a very high extent) were combined, but the mean, standard deviation, Cronbach alpha, and average inter-item correlation are for all five options in the Likert scale. The mean in Table 1 suggests that many respondents tended to choose the high end of the scale as the lowest average is 2.75 and the highest is 3.85 . Table 1 shows that according to $63 \%$ of the respondents, job behaviour that is against BCMM interests is mostly caused by lack of security for BCMM assets, greed (61\% of the respondents), and protection from relatives and friends for those accused of job misbehaviour such as fraud and corruption (58\% of the respondents). The fact that lack of security for BCMM assets is ranked high among the factors that compromise the job performance and job behaviour of the workers is indicative of gaps in the BCMM systems that enable inappropriate job behaviour practices. Unclear job procedures were identified by $37 \%$ of the respondents as a contributing factor towards the workers' inappropriate job performance and behaviour. Section 53 (5) of the Local Government Municipal Systems Act 2000 seeks to ensure that the clarification of the roles and responsibilities of the respective role players makes efficient and timeous governance possible (SALGA, 2011). Efficient and timeous governance at the BCMM seems to have been compromised by its internal procedures that negatively affect job performance according to $37 \%$ of the respondents. However, the majority (56\%) thought the internal procedures did not negatively affect job performance while $7 \%$ had no opinion on this matter.

The fact that only $12 \%$ of the respondents attribute job behaviour that is against BCMM interests to ignorance, shows that only a small share of inappropriate job behaviour and performance practices are erroneous due to ignorance and misunderstanding. Most of the inappropriate job behaviour and performance practices are purposeful with some level of understanding of the wrongfulness of the act and with the capacity to prevent or avoid it. That is why pumping more money towards skills development may not be an appropriate solution to this challenge, because some views in the skills development discourse suggest that there is capacity shortage, hence the inappropriate job behaviour and performance challenge. On the contrary, when the inappropriate job behaviour and 
performance is purposeful, it means that the workers tend to use their capacity for wrongful ends in lieu of using it only for undertaking their occupational responsibilities. It also suggests that the workers are capable of doing their jobs, but choose to pursue ulterior interests in line with the adage of knowing the rules well enough in order to know which one to break without being noticed. This suggests that human nature and work environment could be fuelling the inappropriate job behaviour and performance challenge at the BCMM, hence Singh's (2011) cautionary note that "the human factor is not secondary" (p. 498) in the labour process.

The responses also suggest that some managers struggle to exercise control in their respective departments due to internal and external factors. Many people in BCMM management are in acting positions. They hope for permanent appointment, which they believe depends on them pleasing the relevant stakeholders. One respondent refers to the BCMM as "Hollywood because everyone is acting in a position they are still studying to be in or on sick leave. BCMM is an extended wing of St Marks Hospital." The acting capacity of many workers renders them indecisive when tough and unpopular decisions have to be taken. For instance, some respondents suggest that a line manager may follow all procedures for dealing with poorly performing and/or inappropriately behaving workers, but when managers exhaust the applicable corrective measures without achieving the desired outcomes, then punitive ones should be used. This may include sacking the workers in question. However, the municipal manager as the accounting officer of the municipality has the authority to hire and fire workers after all proper procedures have been followed. Since all municipal managers were in acting positions from November 2008 to March 2012 when the current municipal manager was appointed permanently, they did not want to jeopardise their chances of permanent employment in this position. Consequently, they usually refused to fire poorly performing and inappropriately behaving workers. Instead, they asked the manager concerned, who has no authority to fire someone, to deal with the matter, thereby expecting him or her to use corrective measures indefinitely. This compromises management authority and under such circumstances, some workers may take advantage of the environment because they know that no negative consequences will follow their inappropriate job behaviour and performance.

Despite the challenges with acting municipal managers, it is important to note that the enforcement of disciplinary measures is not solely this official's responsibility. According to the BCMM Key Performance Indicators (KPA) Achievement Report (2011c, pp. , 36), the Labour Relations Division of the Human Resources Department "is responsible for employment relations and maintenance of discipline at the workplace." The Report further notes that the responsibility of the Labour Relations Division also includes ensuring that line managers are capacitated in all aspects of labour relations so as to be able to exercise control and diligently discharge their duties. The Labour Relations Division also ensures the implementation and enforcement of the collective agreement disciplinary code. Consequently, "during the 2010/11 financial year a total of one hundred and forty-six (146) disciplinary hearings was conducted and thirty-one (31) suspension cases and disciplinary enquiries were handled and finalised" (Buffalo City Metropolitan Municipality, 2011, p. 36). Of the 86 submitted grievances, 33 were resolved. To prevent further occurrences of job misbehaviour, the Labour Relations Division conducted road shows to educate workers about expected job behaviour and made them aware of the common misdemeanours that lead to punitive measures against offenders.

It is important to note that 146 disciplinary hearings were conducted in the $2010 / 11$ financial year, that is, when the municipality still had an acting manager. There was mismanagement of employees' unethical behaviour which translated to inaction against offending workers. The collective decision-making process in the disciplinary hearings may have assisted in this regard, mitigating the effects of punitive decision making by managers who are in acting positions. Furthermore, the Local Government Municipal Systems Act (2000, p. 22) requires municipalities to "take measures to prevent corruption." It is commendable that the BCMM is acting against job misdemeanours such as fraud and corruption as evidenced by the suspensions, dismissals and issuing of written warnings to misbehaving workers. However, BCMM measures to prevent corruption seem to be under threat. Expanding on the question "Does the BCMM have an effective policy to get rid of unproductive workers?" one respondent argued that the BCMM does not have such a policy:

The only policy this place has is to try and get rid of good people and cover up corruption. Take the City Manager, he points out the wrong doings of all ..., suddenly he is in the firing line; wonder why; maybe because tenders are not going the way they used to and the CM [City Manager] knows how to say no. 
It also transpired that some BCMM councillors were accused of corruption, even though the Local Government Municipal Systems Act (2000, p. 106) states that a councillor must "perform the functions of the office in good faith, honestly and in a transparent manner; and at all times act in the best interest of the municipality and in such a way that the credibility and integrity of the municipality are not compromised." To curb corruption, the requirements of the Act need to be applied. The same Act (2000, p. 64) requires the municipality, in accordance with the Employment Equity Act (1998) to develop and adopt appropriate systems and procedures to ensure fair, efficient, effective and transparent personnel administration, including (a) the recruitment, selection and appointment of persons as staff members; (b) the supervision and management of staff; (c) the monitoring, measuring and evaluating of performance of staff.

The Local Government Municipal Systems Act (2000, p. 22) requires that there be "a culture of public service and accountability amongst staff." It is, however, difficult to know whether this has been achieved at the BCMM because most of the respondents (53\%) are neutral on the question about whether workers are mindful of the impact of their actions on others. However, $38 \%$ believed that the workers were mindful while only $9 \%$ thought that they were not. With regard to whether workers cared if others suffered as a result of them doing their jobs badly, $34 \%$ of the respondents agreed, $36 \%$ dissented and $30 \%$ were neutral. In terms of the same Local Government Municipal Systems Act (2000, p. 114), the code of conduct for municipal staff members requires them to "foster a culture of commitment to serving the public." However, while $31 \%$ of respondents observed that the quality of service discourages customers from dealing with the BCMM again, $37 \%$ felt that it does not. This shows that more still needs to be done at the BCMM in line with section 95 of the Local Government Municipal Systems Act (2000) which seeks to "establish a sound customer management system that aims to create a positive and reciprocal relationship between persons liable for payments, and the municipality" (SALGA, 2011, p. 9).

Responding to the question as to why some workers engage in inappropriate job behaviour and performance practices, although they have formal educational qualifications, one respondent stressed that:

It is because there is no or little communication with the management of all relevant policies and procedures when employees are newly employed in BCMM. Management is inconsistent in the application of such policies. It depends whether the manager likes or dislikes you and that will determine the outcome of the specific issue. Staff who outshine and go the extra mile in their work are not recognised as there is no performance management system in place, so employees just come and do "that much" and go home, whether it's in line with policy or not, who cares. Lack of genuine care, respect, trust and positivity for each other has greatly diminished and the spirit of Ubuntu is almost dead / already dead. Management too don't comply with the policies, they are just there in black and white, but few if any comply or review such policies. I think for unskilled or semi-skilled employees, it could be that they are less educated and need someone to educate them in their mother tongue about the repercussions of noncompliance.

The fact is that according to $88 \%$ of respondents, some workers know what is right, but still do what is wrong and evidence suggests that human nature and the work environment could be fuelling inappropriate job behaviour and performance. As 52\% of respondents have no opinion in this regard, while $34 \%$ think that they are consistent and $8 \%$ think they are not, it is difficult to ascertain if the policies and practices in the BCMM are consistent in addressing unethical conduct. Moreover, it is difficult to ascertain if the BCMM provides enough protection for people who disclose corruption because 59\% of respondents have no opinion in this regard, $38 \%$ think the BCMM does not provide enough protection and only $2 \%$ think it provides enough protection. The $38 \%$ of respondents who think that BCMM does not provide enough protection could be indicative of BCMM's progress towards the achievement of its good governance strategic objectives for 2011/12. The strategic objectives include the "development of fraud awareness and culture capable of mitigating fraud in a responsible manner" (Buffalo City Metropolitan Municipality, 2011, p. 3). If most people feel vulnerable as a result of exposing fraud and corruption, then very few will have the courage to risk their lives. This is especially so in light of the death threats the municipal manager and his family received as a result of his fight against corruption and these threats attest to the determination by some individuals to continue with corruption by removing people who prevent it (Weekend Post, 2011, Hollands, 2011). This is not unique to the BCMM as whistle-blowers were victimised in other municipalities such as Sol Plaatjie Municipality (Gxoyiya, 2011). 


\section{Inappropriate use of resources for personal purposes}

Evidently, BCMM measures for preventing fraud and corruption are insufficient because the use of BCMM resources for personal purposes continues. Table 2 shows the extent to which specific resources were used for personal purposes. This happened despite the stipulation in the Local Government Municipal Systems Act (2000, p. 118) that "a staff member of a municipality may not use, take, acquire, or benefit from any property or asset owned, controlled or managed by the municipality to which that staff member has no right." That being said, $36 \%$ of respondents believe that workers use what does not belong to them without permission from the owners, while $13 \%$ think this does not happen and 51\% are neutral.

Table 2: Inappropriate Use Of Resources For Personal Purposes

\begin{tabular}{|c|c|c|c|c|c|c|}
\hline Resource & 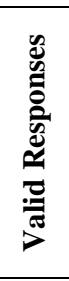 & 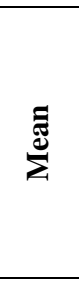 & 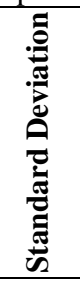 & 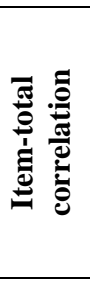 & $\begin{array}{l}\frac{3}{0} \\
\frac{0}{0} \\
\frac{0}{0} \\
:=\frac{\pi}{2} \\
\frac{\pi}{2} \\
\frac{\pi}{4}\end{array}$ & 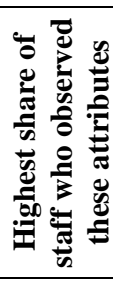 \\
\hline Use of BCMM's vehicles for personal purposes & 315 & 3.62 & 1.23 & 0.81 & 0.84 & $57 \%$ \\
\hline Use of BCMM's phones for personal purposes & 312 & 3.26 & 0.88 & 0.32 & 0.88 & $36 \%$ \\
\hline Use of BCMM's money for personal purposes & 302 & 2.98 & 0.98 & 0.38 & 0.87 & $31 \%$ \\
\hline Use of BCMM's time for personal purposes & 311 & 3.70 & 1.13 & 0.68 & 0.85 & $60 \%$ \\
\hline Use of BCMM's equipment for personal purposes & 308 & 3.64 & 1.16 & 0.73 & 0.85 & $56 \%$ \\
\hline Use of positional authority in the BCMM to pursue personal interests & 310 & 2.91 & 0.92 & 0.30 & 0.88 & $15 \%$ \\
\hline Deceitful use of leave benefits & 309 & 3.42 & 0.90 & 0.57 & 0.86 & $55 \%$ \\
\hline Rewards for favours received which are against the BCMM policies & 308 & 3.97 & 1.04 & 0.79 & 0.84 & $81 \%$ \\
\hline Bribery of BCMM workers & 308 & 3.73 & 1.13 & 0.67 & 0.85 & $58 \%$ \\
\hline Delaying decisions in order to pursue personal interests & 309 & 3.35 & 0.86 & 0.61 & 0.86 & $37 \%$ \\
\hline
\end{tabular}

To get the percentages in Table 2, the last two options (to a high extent and to a very high extent) were combined, but the mean, standard deviation, Cronbach alpha, and average inter-item correlation are for all five options in the Likert scale. The mean in Table 2 suggests that many respondents tended to choose the high end of the scale as the lowest average is 2.91 and the highest is 3.97 . Table 2 also shows that according to $81 \%$ of the respondents, BCMM workers accept rewards for favours received which were against BCMM policies. These include getting inside information regarding tenders, and inducements, rewards, gifts, and favours to municipal officials for the purpose of getting a contract. This buttresses the conviction of the BCMM municipal manager that BCMM "is corrupt to its core at an administration and supply chain management level" (Times Live, 2010, p. 1). According to $60 \%$ of respondents, BCMM's time is used for personal purposes, with 55\% of respondents observing that some workers use their leave benefits deceitfully. Deceitful use of leave benefits includes acquisition of fraudulent certificates, and not reporting for duty on account of being sick while in reality they are not. For this reason, Tanzi (1998, p. 565) emphasises that "not all acts of corruption result in the payment of bribes. For example, a public employee who claims to be sick but goes on vacation is abusing his public position for personal use. Thus, he is engaging in an act of corruption even though no bribe is paid." The rate of absenteeism of BCMM workers is rather high. Although the internationally accepted rate of absenteeism is 3\%, for sick leave only, the BCMM recorded 2.8\%, 3.9\% and 4.4\% in April, May and June 2011 (Buffalo City Metropolitan Municipality, 2011, p. 38). The council then established the Absenteeism Management Committee, whose responsibility was to monitor the rate of absenteeism, investigate its motivation and propose measures to reduce it. It also researched worker absenteeism (at the time of writing this research report, the results of this study had not yet been made public).

Vehicles, according to $57 \%$ of the respondents, and equipment, according to $56 \%$, are also used for personal purposes, yet the Local Government Municipal Systems Act (2000) forbids this practice. This suggests that one has to dig deeper in order to understand the $69 \%$ of respondents who note that there is a shortage of material to use for doing their jobs. Logically, there is bound to be a shortage of such material if workers use it for personal purposes. The cross-tabulation shows that, of the respondents who think there is enough material for all the workers to use in doing their jobs, 86.36\% think that BCMM workers use BCMM's vehicles for personal purposes. This was 
established through a combination of respondents who agree and strongly agree on the question on whether there is enough material for all the workers to use in doing their jobs and those who chose the high and the very high extent on whether BCMM workers use BCMM's vehicles for personal purposes. The relationship between the two variables was found to be statistically significant $\left(\mathrm{Chi}^{2}=380.28, \mathrm{df}=16, \mathrm{p}=0.0000\right)$ with Cramér's $\mathrm{V}=0.56$ which indicates that this finding is of large practical significance. The Spearman correlation coefficient $(0.63)$ indicates that there is moderate correlation between thinking that there is enough material for all the workers to use in doing their jobs and the use of BCMM's vehicles for personal purposes.

Moreover, $31 \%$ of respondents observe that workers use BCMM's money for personal purposes. The crosstabulation shows that, of respondents who think that all BCMM workers can be depended upon to undertake honestly the work assigned to them, 70.58\% thought that BCMM workers used BCMM's resources for personal purposes. This was established through a combination of respondents who agree and strongly agree on the question about whether BCMM workers can be depended upon to undertake honestly the work assigned to them and those who chose high extent and very high extent on the question about whether the workers use BCMM's money for personal purposes. The relationship between the two variables was found to be statistically significant $\left(\mathrm{Chi}^{2}=\right.$ 476.22, $\mathrm{df}=16, \mathrm{p}=0.0000$ ) with Cramér's $\mathrm{V}=0.63$ which indicates that this finding is of large practical significance. The Spearman correlation coefficient $(0.57)$ indicates that there is moderate correlation between thinking that all BCMM workers can be depended upon to undertake honestly the work assigned to them and the use of BCMM's money for personal purposes.

The $37 \%$ of respondents who observed delaying of decisions in order to pursue personal interests could also be referring to the R3.1 million spent on "emergency requisitions" (Nini, 2012c, p. 1). The BCMM's supply chain management policy suggests that "in the normal course of business, procurement of goods and services are allowed either by way of price quotation or through a competitive bidding process" (Public Safety, 2010, p. 13). However, National Treasury (2004, p. 32) states that in emergency cases, that is, "cases where immediate action is necessary in order to avoid a dangerous or risky situation or misery", these processes may be dispensed with and procurement done in any manner that is in the best interests of the department or municipality concerned. Some respondents suggest that some workers take advantage of this and create emergency cases by delaying procurement decisions in order to procure from their accomplices. Such cases make it impracticable to ensure procurement that is "fair, equitable, transparent, competitive and cost-effective" as stipulated in article 217(1) of the Constitution because standard procurement processes are bypassed (Buffalo City Metro Municipality, 2010, p. 204; National Treasury Republic of South Africa, 2004, p. 2). Emergency cases, then make it possible for the selected supplier to charge uncompetitive prices and thereafter share the profits with the official who created the emergency.

The fact that $41 \%$ of respondents hold that all BCMM workers can be depended upon to undertake honestly the work assigned to them needs to be viewed with caution in light of such high level use of BCMM resources for personal purposes. This caution is underscored by the fact that $54 \%$ of respondents think that insincerity is a form of inappropriate job behaviour that occurs in their respective departments. In fact, the cross-tabulation shows that, of the respondents who think all BCMM workers can be depended upon to undertake the work assigned to them honestly, $69.35 \%$ think workers use BCMM's vehicles for personal purposes. This was established through a combination of respondents who agreed and strongly agreed on the question about whether BCMM workers can be depended upon to undertake honestly the work assigned to them and those who chose high extent and very high extent on the question about whether the workers used BCMM's vehicles for personal purposes. The relationship between the two variables was found to be statistically significant $\left(\mathrm{Chi}^{2}=517.98, \mathrm{df}=16, \mathrm{p}=0.0000\right)$ with Cramér's $\mathrm{V}=0.65$ which indicates that this finding is of large practical significance. However, the Spearman correlation coefficient (0.12) indicates that there is no correlation between the notion that BCMM workers can be depended upon to undertake honestly the work assigned to them and the notion that BCMM workers use BCMM's vehicles for personal purposes.

According to $38 \%$ of respondents, the $\mathrm{BCMM}$ views mismanagement of assets like money, vehicles and telephones as a serious offence; $31 \%$ think it does not view it as a serious offence and another $31 \%$ had no opinion one way or the other. Some respondents, however, suggest that if the municipality was serious about its assets, there would not be many people in acting positions because they think that this makes the municipality vulnerable by weakening decision-making on inappropriate job behaviour. Apparently, acting staff do not want to jeopardise their 
chances of permanent employment, and are thus reluctant to take tough decisions. The reverse argument is that people in acting positions could take advantage of the situation and take tough decisions in an effort to prove that they are capable of doing the job to which they should therefore be appointed permanently.

A factor that contributed to thinking that the BCMM does not view mismanagement of its assets as a serious offence is the alleged inefficient treatment of suspension cases. Suspension on full pay and appointment of someone to act in that position means an increase in the municipality's salary expenses because the suspended worker is paid and the one acting has to be paid an acting allowance. These expenses continue until the suspended worker is proven guilty or not guilty by a disciplinary committee or court of law. The longer the disciplinary and/or court processes take, the longer the municipality suffers increased salary expenses. It is then not surprising that many respondents (38\%) think that the BCMM has no effective policy to get rid of unproductive workers, while $28 \%$ think that it does and $33 \%$ are neutral. The high percentage of noncommittal responses, though respondents were promised anonymity, could indicate lack of trust due to the political camps that exist at the BCMM.

The benefits of individual performance are to ensure alignment of individual goals and objectives with that of the organization and to co-ordinate efforts in order to achieve those goals. Managers must clearly understand what is expected from their employees, by when it is expected and to what standard is expected and make qualified decisions within the employee's level of competencies. It is imperative that learning and development opportunities are created for all employees to competently meet their performance targets.

\section{LIMITATIONS}

The advantage of a case study is that it typically includes individuals or institutions with the specific characteristic that is being investigated. What this study sought to establish is not whether there is inappropriate job behaviour and performance at the BCMM. This had already been established by reliable entities such as the Office of the Auditor General, and by parliamentary, municipal and departmental reports. The question is epistemological in nature as it sought to establish how formal education co-existed with inappropriate job behaviour and performance when formal education is meant to eliminate such practices. Although inappropriate job behaviour and performance practices are attributed to the lack of broad skills, it is however difficult to attribute specific inappropriate job behaviour and performance to a particular broad skill component. This is due to the challenge in establishing a causal relationship between attitudes, ethics and values on the one side and particular inappropriate job behaviour and performance on the other. To put it differently, it is not possible to establish that people with, for instance, a certain measure of honesty will display particular job behaviour and performance practices. Such a notion would assume that levels of very honest $/ 100 \%$, honest $/ 75 \%$, neutral $/ 50 \%$, dishonest $/ 25 \%$ and very dishonest $/ 0 \%$ would translate into performing $/ 100 \%$, performing $/ 75 \%$, neutral $/ 50 \%$, poorly performing $/ 25 \%$, and very poorly performing $/ 0 \%$. The inability to establish a causal relationship between attitudes, ethics and values on the one side and particular inappropriate job behaviour and performance practices on the other, has, however, been mitigated through establishment of the extent and nature of broad skills available at the BCMM according to the perception of the respondents. For instance, a question such as "To what extent do BCMM workers use deceitful leave benefits?" reveals levels of honesty in a particular activity as perceived by respondents.

Secondly, the challenge with investigating how broad skills shape workers' job behaviour and performance is that most statistics relating to skills are based on perception. Consequently, there are conflicting voices with some people arguing, for instance, that there is an oversupply of engineers and others claiming that there is a serious shortage. This approach towards skills, characterised by uncertainty, does not augur well for addressing the challenge of inappropriate job behaviour and performance among BCMM workers. To address it, higher levels of certainty are required so as to be in a position to determine and eliminate the particular factors responsible for this behaviour and performance. The study used the mixed method approach to minimise the impact of this limitation, as the mixing of qualitative and quantitative data helped to cushion the weaknesses of each method and the two complement each other. 


\section{CONCLUSION}

By and large, the unquestioning acceptance of the assumption that the skills shortage is responsible for inappropriate workers' job performance and behaviour is discredited by the evidence of skilled personnel who exercise their responsibilities in a manner that undermines their occupational requirements. The evidence further underscored the need to investigate the contradiction of formal education coexisting with inappropriate job behaviour and performance practices. Therefore, it is imperative to realise that the narrow conception of skills that privileges job-specific capabilities is not enough for cultivating a workforce with appropriate job behaviour and performance practices. On the other hand, continuing inappropriate job behaviour and performance challenges the assertion that formal education translates to fewer social problems. The evidence of misappropriation of resources shows that many people involved in this practice have significant levels of formal education. Such evidence of inappropriate job behaviour and performance by the educated makes the achievement of the functionalists' goals for education doubtful, specifically economic development and common good goals. The evidence also reveals the weakness of the functionalist theory which focuses on the positive contributions that education makes to society and overlooks its negative contributions and limitations. Widespread inappropriate behaviour calls the impact of education on job behaviour and performance into question because evidence shows, for instance, that municipal resources are also misappropriated by those with formal education. This is a serious setback for functionalist claims about education as even some of those appointed on academic merit do not reflect appropriate ethics, attitudes and values.

The seriousness of the municipal responsibility necessitates efficacious application of management principles, because the growth and development of every economy hinges on how resources are judiciously managed and increased. Therefore, the application of broad skills and effective management practices is crucial to close the gaps that enable the perpetuation of inappropriate job behaviour and performance in organizations. There is undoubtedly an inappropriate job behaviour and performance at the BCMM despite the fact that more than two thirds of workers have appropriate qualifications. This corroborates the view that functionalists' assumption that formal education is a solution to societal problems needs to be qualified, because, on its own, it is not enough to address this challenge. It further shows that narrow job-specific capability inadvertently enables malpractices like fraud, corruption and embezzlement because without appropriate values, ethics and attitudes it creates a favourable environment for such malpractices to permeate the workplace. The application of broad skills could efficaciously counter the challenge of misappropriation of resources and lead to more appropriate job behaviour and performance in the organizations such as the BCMM. This is because though job-specific capability enhances labour productivity, the paucity of appropriate values, ethics and attitudes can compromise it.

\section{AUTHOR INFORMATION}

Prakash Singh is a professor at the Nelson Mandela Metropolitan University in Port Elizabeth, South Africa. He is an NRF rated researcher and a Fulbright scholar. His niche research areas of publication are organizational behaviour and social psychology. Professor Singh is the author of Innovative Strategies to Develop Better Schools and co-author of Principal Leadership. He has also published widely in peer-reviewed journals and has presented numerous papers at international conferences.

E-mail: Prakash.Singh@nmmu.ac.za

Thembinkosi Twalo is currently employed as a Chief Researcher at the Human Sciences Research Council. His highest qualification is a $\mathrm{PhD}$ degree which he obtained from the Nelson Mandela Metropolitan University in Port Elizabeth, South Africa. His research focus is on job behaviour and performance. He has published several articles in peer reviewed journals and has presented several papers at international conferences.

Email: ttwalo@hsrc.ac.za 


\section{REFERENCES}

Aguinis, H. (2005). Performance management. Edinburgh: Heriot-Watt University.

Bandura, A. (1997). Social learning theory. Englewood Cliffs, NJ: Prentice-Hall.

Bennett, R. J., \& Robinson, S. L. (2000). Development of a measure of workplace deviance. Journal of Applied Psychology, 85, 349-60.

Benya, Z. (2011). The effectiveness of poverty alleviation initiatives in the Buffalo City Metropolitan Municipality (Unpublished MA dissertation). Port Elizabeth, South Africa: Nelson Mandela Metropolitan University.

Boye, M. W., \& Jones, J. W. (1997). Organizational culture and employee productivity. In R.A. Giacalone, \& J. Greenberg (Eds.), Antisocial Behavior in Organizations. Thousand Oaks, CA: SAGE.

Brass, D. J., Butterfield, K. D., \& Skaggs, B. C. (1998). Relationships and unethical behavior: A social network perspective. The Academy of Management Review, 23(1), 14-31.

Brown, M. E., \& Treviño, L. K. (2006). Socialized charismatic leadership, values congruence, and deviance in work groups. Journal of Applied Psychology, 91(4), 954-962.

Brown, M. E., Treviño, L. K. \& Harrison, D. A. (2005). Ethical leadership: A social learning perspective for construct development and testing. Organizational Behavior and Human Decision Processes, 97(2), 117 134.

Buffalo City Metropolitan Municipality. (2010). Buffalo City Metropolitan Annual Report 2009/2010. Retrieved from http://www.buffalocity.gov.za/municipality/annual_report09-10/final/ar0910_part2ch2_pg42-48.pdf

Buffalo City Metropolitan Municipality. (2011). Service Delivery and Budget Implementation Plan for 2011/2012. Buffalo City Metropolitan Municipality. Executive Directorate: Strategic Management. Retrieved from http://www.google.co.uk/\#hl=en\&sclient=psy-...

Buffalo City KPA Achievement Report. (2011). Retrieved from http://www.buffalocity.gov.za/municipality/annual_report10-

Buffalo City Metropolitan Municipality. (2012). Vacancies. Retrieved from http://www.buffalocity.gov.za/municipality/vacancies2012/vacancies_12march12.pdf

Creswell, J. W., \& Plano-Clark, V. L. (2007). Designing and constructing mixed research methods. London: Thousand Oaks.

Dineen, B. R., Lewicki, R. J., \& Tomlinson, E. C. (2006). Supervisory guidance and behavioral integrity: Relationships with employee citizenship and deviant behavior. Journal of Applied Psychology, 91(3), 622635.

Donaldson, T., \& Preston, L. E. (1995). The stakeholder theory of the corporation: Concepts, evidence, and implications. The Academy of Management Review, 20, 65-91.

Employment Equity Act No. 55 of 1998. Department of Labour: Republic of South Africa.

Freeman, R. E. (1984). Strategic management: A stakeholder approach. Marshfield, MA: Pitman.

Giacalone, R. A., \& Greenberg, J. (Eds.). (1997). Antisocial behavior in organizations. Thousand Oaks: SAGE.

Goodpaster, K. E. (2007). Conscience and corporate culture. Oxford: Blackwell Publishers.

Grant, R. M., \& Visconti, M. (2006). The strategic background to corporate accounting scandals. Long Range Planning, 39, 361-83.

Greenberg, J. (2002). Who stole the money, and when? Individual and situational determinants of employee theft. Organizational Behavior and Human Decision Processes, 89(1), 985-1003.

Gxoyiya, A. (2011). Whistleblowers victimised in Sol Plaatjie Municipality. Retrieved from http://www.politicsweb.co.za/politicsweb/view/politicsweb/en/page72308?oid=269695\&sn=Marketingweb + detail\&pid=90389

Hegarty, W. H. \& Sims, H. P. (1979). Some determinants of unethical decision behavior: An experiment. Journal of Applied Psychology, 63(4), 451-457.

Hirschi, T. (1969). Causes of delinquency. Berkeley: University of California Press.

Hollands, B. (2011). Meet Buffalo City's corruption buster. Retrieved from http://theweekendpost.com/tag/andile$\underline{\text { fani/ }}$

Hollinger, R. C., \& Clark, J. P. (1983). Deterrence in the workplace: Perceived certainty, perceived severity and employee theft. Social Forces, 62(2): 398-418.

Jones, T. M., \& Wicks, A. C. (1999). Convergent stakeholder theory. The Academy of Management Review, 24, 206-221. 
Kaptein, M. (2008). Developing a measure of unethical behaviour in the workplace: A stakeholder perspective. Journal of Management, 34(5), 978-1008.

Kaptein, M. (2011). Understanding unethical behaviour by unravelling ethical culture. Human Relations, 64(6), 843869.

Kaseke, L. L. (2011). Challenges facing the Limpopo Department of Public Works with regard to service delivery : A case of the core functions of the Department. Limpopo, South Africa: University of Limpopo.

Kidwell, R. E. \& Martin, C. L. (Eds.). (2005). Managing Organizational Deviance. Thousand Oaks, CA: SAGE.

Local Government Municipal Systems Act No. 32 of 2000. Cape Town: Government Gazette.

Mawonga, T. A. (2012). A critical analysis of the applicability of the King III in the local government sphere: A case of the Buffalo City Metropolitan Municipality in the Eastern Cape from 2009-2011 (Unpublished MA dissertation). Alice, South Africa: University of Fort Hare.

Mazzola, P., Ravasi, D., \& Gabbioneta, C. 2006. How to build reputation in financial markets. Long Range Planning, 39, 385-407.

Merton, R. K. (1938). Social structure and anomie. American Sociological Review, 3, 672-682.

Mitchell, R. K., Agle, B. R., \& Wood, D. J. (1997). Toward a theory of stakeholder identification and salience: Defining the principle of who and what really counts. Academy of Management Review, 22, 853-86.

Mokone, T., \& De Kock, R. (2014). The Herald, 31 July 2014.

Municipal Structures Act. (1998). Local Government: Municipal Structures Act 117 of 1998. Government Gazette. December 18, 1998. Retrieved from: http://www.info.gov.za/view/DownloadFileAction?id=70652

National Treasury Republic of South Africa. (2004). Supply Chain Management: A Guide for Accounting Officers / Authorities. Retrieved from www.environment.gov.za/sites/default/.../accountingofficer_scmguide.pdf

Nini, A. (2012). BCM wastes R150m in year. Retrieved from http://www.dispatch.co.za/bcm-wastes-r150m-in-year/

Overstrand Municipality. (2014). Performance management system: Implementation policy. Johannesburg: Proactive Management Services.

Public Safety. (2010). Supply Chain Management Policy: Public Safety. Retrieved from http://www.nwpg.gov.za/public_safety/PSCircular_1.html

Robertson, D. C. \& Rymon, T. (2001). Purchasing agents' deceptive behavior: A randomized response technique study. Business Ethics Quarterly, 11(3), 455-479.

Schein, E. H. (1985). Organizational culture and leadership. San Francisco, CA: Jossey-Bass.

Schminke, M., Ambrose, M. L., \& Neubaum, D. O. (2005). The effect of leader moral development on ethical climate and employee attitudes. Organizational Behavior and Human Decision Processes, 97(2), $135-151$.

Schweitzer, M. E., Ordóñez, L., \& Douma, B. (2004). Goal setting as a motivator of unethical behavior. Academy of Management Journal, 47(3), 422-432.

Singh, P. (2011). SWEAT analysis to determine organisational effectiveness. In W. H. Jonathan (Ed.), Examining job satisfaction: Causes, outcomes and comparative differences. Champaign, IL: Common Ground.

Singh, P. (2013a). A collegial approach in understanding leadership as a social skill. International Business and Economics Research Journal, 12(5), 489-502.

Singh, P. (2013b). Fear abounds in the educational environment: Teachers' professional competencies in the management of knowledge. International Business and Economics Research Journal, 12(6), 687-700.

Singh, P., Manser, P., \& Dali, C. (2013). Principal leadership. Saarbrucken, Germany: LAP LAMBERT Academic Publishing.

Singh, P., \& Twalo, T. (2014). The impact of internal organizational factors on the inappropriate job performance and behaviour of employees: A case study. International Business and Economics Research Journal, 13(5), 939-954.

South African Local Government Association (SALGA). (2011). Guideline document on the roles and responsibilities of councillors, political structures and officials. Retrieved from http://www.salga.org.za/pages/Knowledge--Hub/Guidelines-for-Municipalities

Stokes, G. (2010). South Africa Inc laments skills shortage. . Retrieved from: http://www.fanews.co.za/article.asp?Front_Page_Features 25,Straight_Talk 1146,South_Africa_Inc lame nts_skills_shortage 7443

Tang, T. L. P., Chen, Y. J., \& Sutarso, T. (2008). Bad apples in bad (business) barrels. Management Decision, 46(2), 243-263.

Tanzi, V. (1998). Corruption around the world causes, consequences, scope, and cures. IMF Staff Papers, 45(4), 559-594. 
Times Live. (2010). Buffalo City corrupt to the core. Retrieved from http://www.timeslive.co.za/local/article765209.ece/Buffalo-City-Corrupt-to-the-core

Times Live. (2012). Reality check on services. Retrieved from http://www.timeslive.co.za/thetimes/2012/07/24/reality-check-on-services

Treviño, L. K. (1986). Ethical decision making in organizations: A person-situation interactionist model. Academy of Management Review, 11(3), 601-617.

Treviño, L. K., \& Brown, M. E. (2005). The role of leaders in influencing unethical behavior in the workplace. In R.E. Kidwell, \& C.L. Martin (Eds.), Managing organizational deviance. Thousand Oaks, CA: SAGE.

Treviño, L. K., \& Weaver, G. R. (2003). Managing ethics in business organizations: Social scientific perspectives. Stanford: Stanford University Press.

Treviño, L. K., Weaver, G. R., \& Reynolds, S. J. (2006). Behavioral ethics in organizations: A review. Journal of Management, 32, 951-90.

Vardi, Y., \& Weitz, E. (2004). Misbehavior in organizations: Theory, research, and management. Mahwah, NJ: Lawrence Erlbaum Associates.

Weekend Post. (2011). Meet Buffalo City's corruption buster. Retrieved April 25, 2012, from http://theweekendpost.com/tag/east-london/ 


\section{NOTES}

